\title{
A Brucella melitensis $\mathrm{H} 38 \Delta w b k F$ rough mutant protects against Brucella ovis in rams
}

\author{
Pilar M. Muñoz ${ }^{1,2^{*}}$ (D) Raquel Conde-Álvarez³, Sara Andrés-Barranco ${ }^{1,2}$, María-Jesús de Miguel $^{1,2}$, \\ Amaia Zúñiga-Ripa ${ }^{3}$, Beatriz Aragón-Aranda ${ }^{3}$, Miriam Salvador-Bescós ${ }^{3}$, Estrella Martínez-Gómez ${ }^{3,4}$, \\ Maite Iriarte ${ }^{3}$, Montserrat Barberán ${ }^{5}$, Nieves Vizcaíno ${ }^{6}$, Ignacio Moriyón ${ }^{3}$ and José M. Blasco ${ }^{1,2}$
}

\begin{abstract}
Brucella melitensis and Brucella ovis are gram-negative pathogens of sheep that cause severe economic losses and, although B. ovis is non-zoonotic, B. melitensis is the main cause of human brucellosis. B. melitensis carries a smooth (S) lipopolysaccharide (LPS) with an N-formyl-perosamine O-polysaccharide (O-PS) that is absent in the rough LPS of $B$. ovis. Their control and eradication require vaccination, but $B$. melitensis Rev 1 , the only vaccine available, triggers antiO-PS antibodies that interfere in the S-brucellae serodiagnosis. Since eradication and serological surveillance of the zoonotic species are priorities, Rev 1 is banned once B. melitensis is eradicated or where it never existed, hampering B. ovis control and eradication. To develop a B. ovis specific vaccine, we investigated three Brucella live vaccine candidates lacking N-formyl-perosamine O-PS: Bov::CA $\triangle$ wadB $\left(\mathrm{CO}_{2}\right.$-independent B. ovis with truncated LPS core oligo-

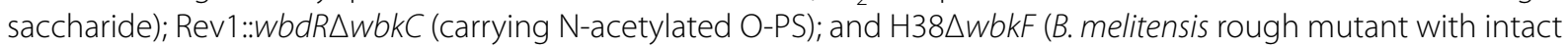
LPS core). After confirming their attenuation and protection against $B$. ovis in mice, were tested in rams for efficacy. H38 $\triangle$ wbkF yielded similar protection to Rev 1 against B. ovis but Bov::CA $\triangle$ wadB and Rev $1::$ wbdR $\triangle$ wbkC conferred no or poor protection, respectively. All H38 $\triangle$ Wb KF vaccinated rams developed a protracted antibody response in ELISA and immunoprecipitation B. ovis diagnostic tests. In contrast, all remained negative in Rose Bengal and complement fixation tests used routinely for B. melitensis diagnosis, though some became positive in S-LPS ELISA owing to LPS core epitope reactivity. Thus, $\mathrm{H3} 3 \triangle \mathrm{wb}$ KF $F$ is an interesting candidate for the immunoprophylaxis of $B$. ovis in $B$. melitensis-free areas.
\end{abstract}

Keywords: Sheep, brucellosis, Brucella, B. ovis, rough, vaccine

\section{Introduction}

Brucellosis is a worldwide extended disease caused by gram-negative bacteria of the genus Brucella that has a severe impact on animal and human health [1]. The genus includes several species among which $B$. melitensis primarily produces brucellosis in sheep and goats and is the major cause of human brucellosis [2]. B. melitensis cells have a surface smooth (S)-type lipopolysaccharide

*Correspondence: pmmunnoz@cita-aragon.es

1 Departamento de Ciencia Animal, Centro de Investigación y Tecnología Agroalimentaria de Aragón (CITA), Zaragoza, Spain

Full list of author information is available at the end of the article
(LPS) made of a lipid A-core oligosaccharide linked to an $\mathrm{N}$-formylperosamine O-polysaccharide (O-PS) that carries the epitopes relevant in S Brucella serodiagnostic tests [3]. Sheep can also be infected by B. ovis, a species that displays a rough (R) LPS because it lacks a complete set of functional O-PS genes [4,5]. Although nonzoonotic, $B$. ovis causes a serious disease manifested by genital lesions in rams and placentitis and abortions in ewes that result in important economic losses [6].

While some countries have eradicated B. melitensis through the combined use of vaccination and test and slaughter programs $[7,8]$, none has eradicated $B$. ovis. Attempts to eradicate B. ovis infection, sometimes

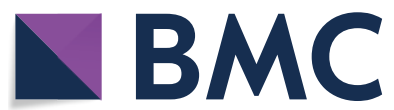

(c) The Author(s) 2022. Open Access This article is licensed under a Creative Commons Attribution 4.0 International License, which permits use, sharing, adaptation, distribution and reproduction in any medium or format, as long as you give appropriate credit to the original author(s) and the source, provide a link to the Creative Commons licence, and indicate if changes were made. The images or other third party material in this article are included in the article's Creative Commons licence, unless indicated otherwise in a credit line to the material. If material is not included in the article's Creative Commons licence and your intended use is not permitted by statutory regulation or exceeds the permitted use, you will need to obtain permission directly from the copyright holder. To view a copy of this licence, visit http://creativecommons.org/licenses/by/4.0/. The Creative Commons Public Domain Dedication waiver (http://creativeco mmons.org/publicdomain/zero/1.0/) applies to the data made available in this article, unless otherwise stated in a credit line to the data. 
misnamed ovine epididymitis, have often been focused exclusively on ram testing and culling, a strategy that has failed consistently because it overlooks the important epidemiological role of ewes [9-11]. Moreover, testing and culling becomes economically unfeasible when prevalence is moderate or high, making vaccination against $B$. ovis indispensable $[11,12]$. Nevertheless, the only vaccine available for the immunoprophylaxis of $B$. melitensis and B. ovis is B. melitensis Rev 1, a live-attenuated S strain that elicits antibodies to the O-PS that interfere in $B$. melitensis serodiagnostic tests. Since these vaccinal antibodies encumber $B$. melitensis eradication and surveillance and this zoonotic species is a priority, Rev 1 is banned after $B$. melitensis eradication, and the same reasons make Rev 1 unsuitable for use in $B$. melitensis-free countries but yet affected by $B$. ovis. Hence, the development of $B$. ovis-specific vaccines is of great interest, as proven by the dramatic increase in B. ovis prevalence in European Union countries shortly after Rev 1 withdrawal $[6,13]$.

Altering the antigenic structure of S Brucella has been the preferred strategy to develop vaccines that circumvent the interference in $\mathrm{S}$ serological tests. Logically, O-PS removal was the first choice and some $\mathrm{R}$ mutants have been investigated as $B$. ovis vaccines. The empirically developed $B$. abortus RB51 (the only R vaccine currently marketed) does not confer adequate protection against either B. melitensis or B. ovis $[14,15]$. However, experiments in mice show that genetically well-defined $R$ vaccines are superior to RB51 and could be effectual against $B$. ovis [16]. An antigen removal strategy was also followed to obtain a $B$. melitensis Rev 1 lacking protein BP26 but, although effective against $B$. ovis, this Rev 1 derivative obviously triggers anti-O-PS antibodies and the associated BP26-iELISA is not sensitive enough to be used as differential test [17]. Following a positive tagging strategy, a Rev 1 vaccine carrying the green fluorescent protein (GFP) gene and its ancillary GFP-ELISA were investigated in sheep [18]. Yet, co-inoculation of the GFP-tagged vaccine with soluble GFP plus a GFP booster in Freund's adjuvant ten weeks later are necessary to trigger GFP antibodies matching the persistence of O-PS antibodies, a protocol of no practical use. Finally, Rev1:: wbdR $\Delta w b k C$, a construct carrying $w b d R$ (an E. coli LPS acetyl-transferase gene) instead of $w b k C$ (the Brucella LPS formyl-transferase gene) conferred protection against $B$. ovis in mice and displayed a $\mathrm{N}$-acetyl-perosamine O-PS structure triggering antibodies that could be differentiated from those induced by $B$. melitensis in this laboratory model [19].

Since it is a naturally $\mathrm{R}$ species, a homologous $B$. ovis vaccine could also be an alternative to Rev 1 . Classical bacterins in adjuvant are unsatisfactory as $B$. ovis vaccines $[10,12]$ and, although adjuvant-encapsulated outer membrane-rich extracts are effective [20,21], the complexity of their preparation and the need for revaccinations make these vaccines expensive and unpractical. Recently, a polymeric BLSOmp31 antigen in oil adjuvant has been proposed as a B. ovis vaccine but the vaccine did not prevent infection in rams [22, 23]. An alginate-encapsulated $B$. ovis mutant in a putative $A B C$ transporter has been reported to confer perfect protection in rams [24, 25 ] but this claim was based on a deficient bacteriological search for the challenge strain as only minimal aliquots of diluted homogenates were cultured and some important target organs [26] were not examined. In mice, we have reported that Omp25d and Omp22 mutants, a triple Omp10-Omp31-SP41 mutant and mutants with a truncated LPS-core lateral branch are attenuated and protect against $B$. ovis [27-29]. In parallel, we have investigated $B$. ovis $\mathrm{CO}_{2}$-dependence, a characteristic of this species that would encumber a practical use of homologous vaccines. This trait relates to mutations in carbonic anhydrase (CA) genes and can be abrogated by insertion of $\mathrm{CA}$ homologues of $\mathrm{CO}_{2}$-independent brucellae without affecting virulence in mice [30,31].

In this work, we pursued three of the above-summarized strategies to develop $B$. ovis vaccines minimizing the interference in O-PS serological tests. For the $\mathrm{R}$ vaccine approach, we investigated a B. melitensis $\mathrm{H} 38$ wbkF mutant carrying an R-LPS with intact core oligosaccharide. This choice was based on previous works that show that dysfunction of this gene in this strain, while not matching Rev 1 , results in adequate attenuation and better protection against $B$. melitensis in sheep than that obtained with mutants in other LPS genes [32, 33]. In the Rev 1 background, we studied the above-described

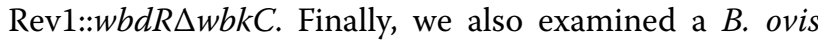
$\mathrm{CO}_{2}$-independent construct deleted in $\mathrm{wadB}$, a gene necessary for full assembly of the R-LPS core oligosaccharide lateral branch of brucellae.

\section{Materials and methods}

Bacterial strains, conservation and growth conditions

The parental strains used for the construction of the vaccine candidate mutants are described below. Bov::CA is a $B$. ovis PA derivative carrying the active carbonic anhydrase (CAI and CAII) genes of B. abortus $2308 \mathrm{~W}$ in a stable $\mathrm{Tn} 7$ insert in chromosome II that is $\mathrm{CO}_{2}$-independent and retains the virulence of the wild-type in the mouse model $[30,31]$. B. melitensis $\mathrm{H} 38$ is a $\mathrm{S}$ virulent strain used previously in the analysis of LPS genes [32], and $B$. melitensis Rev 1 is the OIE recommended sheep brucellosis vaccine [34].

B. ovis PA (wild-type, virulent, serum and $\mathrm{CO}_{2}$-dependent) and its kanamycin-resistant virulent 
derivative (BoPA- $\mathrm{Km}^{\mathrm{R}}$ ) have been respectively used as challenge strains in sheep and mice in previous works $[19,35]$.

All the above bacteria and the corresponding mutants (see below) were maintained freeze-dried or in skimmed milk at $-80{ }^{\circ} \mathrm{C}$ in the CITA (Zaragoza, Spain) Brucella culture collection. To prepare the bacterial suspensions for the experiments described below, the stocks were rehydrated or thawed and seeded onto Blood Agar Base (BAB no. 2, OXOID, USA) or BAB with $5 \%$ sterile calf serum (BAB-S, for B. ovis PA) plates, for 3-4 days at $37^{\circ} \mathrm{C}$ in air or, for $\mathrm{B}$. ovis $\mathrm{PA}$, in $10 \% \mathrm{CO}_{2}$ atmospheres.

\section{Construction and characteristics of vaccine candidates}

The origin and characteristics of the primers and plasmids used in this work are presented in Additional files 1 and 2, respectively.

Bov:: $C A \triangle w a d B$ was constructed using the suicide plasmid pJQK $\triangle$ wadB (pYRI-2 in [36]), which was introduced into Bov::CA by conjugation with E. coli S17 $\lambda$ pir [37]. The first recombination event was selected by nalidixic and kanamycin resistance and the double recombination by nalidixic and sucrose resistance, and kanamycin sensitivity. Deletion of $w a d B$ was confirmed by PCR using oligonucleotides $w a d B-F 1$ and $w a d B$-R4 (Additional file 1), which amplified a fragment of 570 base pairs (bp) in the mutant and a fragment of $1011 \mathrm{bp}$ in the sibling revertant strain. Oligonucleotides $w a d B-F 1$ and $w a d B-R 5$ (Additional file 1), which amplify a fragment of 471 bp only in the wild-type strain, were used to verify the deletion.

Brucella melitensis $\mathrm{H} 38 \Delta w b k F$ ( $\mathrm{R}$ mutant in-frame deleted in the bactoprenol priming for O-PS polymerization gene; henceforth $\mathrm{H} 38 \Delta w b k F$ ) was constructed using the same methodology and genetic tools described for the homologous B. suis Bs $2 \Delta w b k F$ mutant [38]. Briefly, $\mathrm{pJQK} \Delta w b k F$ was transformed into competent $E$. coli S17 $\lambda$ pir (Additional file 2) and, after conjugation with B. melitensis $\mathrm{H} 38$, the first recombination event was selected by nalidixic acid and kanamycin resistance, and the double recombination by nalidixic and sucrose resistance, and kanamycin sensitivity. Deletion of $w b k F$ was confirmed by PCR using oligonucleotides $w b k F$-F1 and $w b k F$-R4 (Additional file 1), which amplified a fragment of $953 \mathrm{bp}$ in the mutant and a fragment of $1796 \mathrm{bp}$ in the sibling revertant strain. Oligonucleotides $w b k F-\mathrm{F} 1$ and wbkF-R6 (Additional file 1), which amplified a fragment of 680 bp only in the wild-type strain, were used to verify the deletion.

Rev1:: wbdRAwbkC construction and characterization has been described in a previous work [19]. Briefly, Rev1:: $w b d R$ was obtained inserting $w b d R$ in chromosome II of B. melitensis Rev 1 using a Tn7 strategy [39]. Then, wbkC (formyltransferase gene) was deleted to obtain
Rev1::wbdR $\Delta w b k C$, which carries $N$-acetyl-perosamine instead of $\mathrm{N}$-formyl-perosamine as proved by immunochemical and NMR analyses [39].

All vaccine candidates were stored at $-80{ }^{\circ} \mathrm{C}$ in skimmed milk and grown as described above.

\section{Virulence and protection studies in mice}

These experiments were carried out using seven-weekold female BALB/c mice (ENVIGO, Harlan) that were maintained in a BSL-3 facility (ES/31-2010-000132) with water and food ad libitum for 2 weeks before and during the experiments in accordance with the current European (directive 86/609/EEC) and Spanish (RD 53/2013) legislations.

To obtain inocula, fresh cultures (see "Bacterial strains, conservation and growth conditions") were harvested in buffered saline solution (BSS; $0.015 \mathrm{M} \mathrm{NaCl}, 7 \mathrm{mM}$ $\left.\mathrm{KH}_{2} \mathrm{PO}_{4}, 10 \mathrm{mM} \mathrm{K} \mathrm{HPO}_{4} ; \mathrm{pH} 6.85\right)$ and suspensions adjusted spectrophotometrically $(600 \mathrm{~nm})$ to the appropriate dose (see below). Purity, absence of S-R dissociation (when appropriate) and exact doses (triplicate measurements) were assessed retrospectively following standard protocols [40].

The virulence and protection assessment in mice of Rev1::wbdR $\Delta w b k C$ and Rev 1 parental strain have been published previously [19]. For virulence assessment of $\mathrm{H} 38 \Delta w b k F$ and Bov::CA $\Delta w a d B$ mutants (this work), groups of 5 mice were inoculated intraperitoneally with the doses established as optimal (Figure 1) in preliminary experiments (not shown). The three vaccine candidates

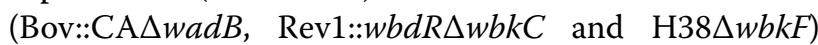
were inoculated at $10^{8} \mathrm{CFU} /$ mouse, a dose considered optimal for immunization with $\mathrm{R}$ mutants in previous experiments in mice [30, 32]; BoPA and Bov::CA parental strains were inoculated at $5 \times 10^{6} \mathrm{CFU} /$ mouse, as established previously [31]. Also, the lowest dose of B. melitensis $\mathrm{H} 38\left(10^{4} \mathrm{CFU} /\right.$ mouse $)$ inducing a suitable spleen colonization was determined in preliminary experiments (not shown). Mice were euthanized at two different time points, selected for each mutant according previous works [19, 31, 32]: the first point corresponds to the expected "peak of multiplication" (week 1 and week 3 for B. melitensis and B. ovis strains, respectively) and the second one, to a later stage of infection (week 5 or 8 ). The residual virulence was determined by plating spleen homogenates on the appropriate agar medium (see above) and calculating the mean $\log _{10} \mathrm{CFU} /$ spleen $\pm \mathrm{SD}$ [41].

To evaluate the protective efficacy, groups of 5 mice were vaccinated subcutaneously with $10^{8} \mathrm{CFU}$ of each vaccine candidate $[19,32]$. Controls were similar groups vaccinated with $10^{5} \mathrm{CFU}$ of Rev 1 or inoculated with BSS as a placebo vaccine. All mice were challenged with 
$5 \times 10^{6} \mathrm{CFU}$ of BoPA- $\mathrm{Km}^{\mathrm{R}}$ (see above) administered intraperitoneally 4 weeks after vaccination. The mean $\log _{10} \mathrm{CFU} /$ spleen $\pm \mathrm{SD}$ of the challenge strain in each group was determined 2 weeks later by plating spleen homogenates on BAB-S supplemented with kanamycin $(50 \mu \mathrm{g} / \mathrm{mL})$ and incubation for 3-5 days in $10 \% \mathrm{CO}_{2}$. Results were compared statistically (one-way ANOVA and Fisher's Protected Least Significant Differences PLSD- post-hoc tests) with those of unvaccinated (BSS) and $\operatorname{Rev} 1$ vaccinated controls.

\section{Ram vaccination and challenge}

The experiment in rams was performed in compliance with the current European (86/609/EEC) and Spanish (RD 53/2013) legislations on the use and protection of experimental animals.

Sixty-nine 4-month-old brucellosis-free Rasa Aragonesa rams of similar weight and body condition were randomly allotted and maintained in five separate pens throughout the experiment. To prepare the inocula, suspensions of bacteria (grown and harvested in BSS as described above) were adjusted spectrophotometrically $(600 \mathrm{~nm})$ to the appropriate concentration $\left(10^{9} \mathrm{CFU} /\right.$ $\mathrm{mL}$ for Rev $1,10^{10} \mathrm{CFU} / \mathrm{mL}$ for the mutant candidates and $10^{11} \mathrm{CFU} / \mathrm{mL}$ for B. ovis PA challenge strain). Purity, absence of S-R dissociation (when appropriate) and exact doses (triplicate measurements) were assessed retrospectively [40]. In the same day, three groups of 14 rams each were immunized subcutaneously in the left elbow with $4 \mathrm{~mL}$ of each vaccine candidate. As controls, a fourth group $(n=14)$ was vaccinated with $2 \mathrm{~mL}$ of Rev 1 and a fifth group $(n=13)$ was kept unvaccinated. Retrospective assessment showed that each ram received $9.6 \times 10^{9} \mathrm{CFU}$ of Bov::CA $\triangle w a d B, 2.5 \times 10^{10} \mathrm{CFU}$ of Rev1::wbdR $\Delta w b k C$, $2.5 \times 10^{10} \mathrm{CFU}$ of $\mathrm{H} 38 \Delta w b k F$ and $1.6 \times 10^{9} \mathrm{CFU}$ of Rev 1 . In the next two weeks, all rams were inspected for rectal temperature and local reactions at the inoculation site every two days.

Eight months after vaccination (when Rev 1 and the vaccine candidates had been cleared [33]), rams were challenged with $2.5 \times 10^{9} \mathrm{CFU}$ in $100 \mu \mathrm{L}$ (determined by retrospective assessment) of $B$. ovis PA given by both conjunctival $(50 \mu \mathrm{L})$ and preputial $(50 \mu \mathrm{L})$ routes, and then clinically examined at weekly intervals. Eight weeks after challenge, they were euthanatized for bacteriological examination. For this, large portions of spleen and epididymides, the whole vesicular glands and ampullae, and the whole cranial (submaxillary, parotid and retropharyngeal), iliac, scrotal, prefemoral and superficial cervical lymph nodes were collected and submitted to culture on a suitable selective medium (see below). Briefly, each organ sample was degreased, superficially sterilized by gentle burning and homogenized in minimal amount of BSS (1 mL per $10 \mathrm{~g}$ of tissue, approx.) using a stomacher. Each tissue homogenate was cultured by plating $1 \mathrm{~mL}$ in each of duplicate plates of CITA medium [42]. Cultures were examined under a stereomicroscope after 5-7 days of incubation at $37^{\circ} \mathrm{C}$ in a $10 \% \mathrm{CO}_{2}$ atmosphere, and suspicious colonies streaked on BAB-S plates for identification by both standard procedures [40] and Bruce-ladder multiplex PCR [43]. A ram was classified as infected if at least one B. ovis PA CFU was isolated from any of the organs or lymph nodes sampled. The infection level of each sample was semi-quantitatively scored as follows: level 1, 1-5 CFU/plate; level 2, 6-25 CFU/plate; level 3, 26-125 CFU/plate; level 4, 126-250 CFU/plate; and level $5,>250 \mathrm{CFU} /$ plate (samples with level equal or higher than 3 were considered as severely infected, and rams showing at least one severely infected organ were counted as severely infected animals). Statistical comparisons of numbers of B. ovis infected (and severely infected) animals were made by Chi-square test (FisherYates correction was applied when required). Numbers of infected (and severely infected) organs per animal were compared by STEPBOOT MULTTEST (5.0, SAS Institute Inc. Copyright $\odot$ ).

For serological studies, blood samples were taken before vaccination, one week after vaccination and every two or three weeks (including one week after challenge) until the end of the experiment.

\section{Serological tests}

The Rose Bengal (RBT) and the complement fixation (CFT) tests for S Brucella were performed according to standard methods [34], and the S-LPS iELISA was performed as described before [44] using gold standard sera (from $46 \mathrm{~B}$. melitensis culture positive and 78 brucellosis-free sheep) to determine the appropriate cut-off. The agar gel immunodiffusion (AGID) test for the serodiagnosis of B. ovis [45] was performed in $3 \mathrm{~mm}$ thick gels of $1 \%$ Noble Agar (Difco, USA) in borate buffer $(0.1 \mathrm{M}, \mathrm{pH}$ 8.3) $-10 \% \mathrm{NaCl}$ using the recommended B. ovis REO 198 hot saline (HS) extract (rich in outer membrane proteins and R-LPS [46]) as antigen, and presence of precipitation bands was examined after $48 \mathrm{~h}$ of incubation at room temperature in a humid chamber. In addition, depending on the vaccine candidate (see "Results"), the antibody response was also examined by indirect ELISA (iELISA) using the appropriate antigen as described below.

The iELISA with HS extract of either B. ovis PA or Bov::CA $\Delta w a d B$ was performed on standard 96-well polystyrene plates (Costar ${ }^{\circledR}$, USA). Optimal coating conditions (antigen at $2.5 \mu \mathrm{g} / \mathrm{mL}$ in carbonate buffer $[0.06 \mathrm{M}$, $\mathrm{pH}$ 9.6] at $37{ }^{\circ} \mathrm{C}$ overnight), serum dilution (1/100) and conjugate (recombinant Protein G-HRPO, Thermo Fisher Scientific, USA at $0.2 \mu \mathrm{g} / \mathrm{mL}$ ) were determined 
by previous titration with gold-standard sera from 46 B. ovis culture-positive and 78 brucellosis-free sheep. A $0.1 \%$ solution of 2, 2-azinobis, 3-ethyl-benzothiazoline sulfonic acid diammonium salt (ABTS; Sigma Chemical Co., USA) with $0.004 \% \mathrm{H}_{2} \mathrm{O}_{2}$ in citrate buffer $(0.05 \mathrm{M}$, $\mathrm{pH} 4$ ) was used as the substrate, and optical density readings $\left(\mathrm{OD}_{405 \mathrm{~nm}}\right.$, Labsystems Multiskan $\left.\mathrm{RC}\right)$ obtained after 15 min of incubation at room temperature. Results were expressed as the percentage of $\mathrm{OD}_{405 \mathrm{~nm}}$ with respect to a positive control serum. Under these conditions, sera showing $\% \mathrm{OD}_{405 \mathrm{~nm}}$ above $40 \%$ (cut-off resulting in 100\% specificity and maximum [98\%] sensitivity with the gold standard sera) were considered positive.

An iELISA with $\mathrm{N}$-acetyl-perosamine O-PS was performed using a LPS rich extract of the previously described B. abortus $2308 \mathrm{~W} w b d R \Delta w b k C$ construct [19]. This $w b d R \Delta w b k C$-iELISA was optimized using the same panel of gold-standard sera employed in the standard S-LPS ELISA (see above). Costar ${ }^{\circledR}$ plates were coated with $2.5 \mu \mathrm{g} / \mathrm{mL}$ of antigen in carbonate buffer $(\mathrm{pH}$ 9.6) at $37{ }^{\circ} \mathrm{C}$ overnight. Sera were tested at $1 / 100$ dilution and the Protein-G-HRP $(0.2 \mu \mathrm{g} / \mathrm{mL})$ and the ABTS$\mathrm{H}_{2} \mathrm{O}_{2}$ mixture described above were used as conjugate and substrate, respectively. The $\mathrm{OD}_{405 \mathrm{~nm}}$ readings and $\% \mathrm{OD}_{405 \mathrm{~nm}}$ were obtained as described above and sera showing $\% \mathrm{OD}_{405 \mathrm{~nm}} \geq 50 \%$ (optimal cut-off) were scored as positive.

\section{Results}

\section{Characterization of vaccine candidates}

Table 1 summarizes the relevant characteristics of the vaccine candidates investigated. Analyses by SDS-PAGE and Western blot with monoclonal antibody A68/24G12/ A08 (which discriminates intact and truncated Brucella LPS core oligosaccharides [36]) and polyclonal sera of the appropriate specificity [39], confirmed that the three candidates displayed the phenotype predicted according to previous works with homologous or heterologous Brucella mutants and constructs: (i) H38 $\Delta w b k F$ carried a R-LPS with a complete core; (ii) Bov::CA $\Delta$ wadB R-LPS showed the molecular weight shift and epitope defect that correspond to a truncated LPS core lateral branch; and (iii) Rev1::Tn7wbdR $\Delta w b k C$ displayed the shorter $\mathrm{O}-\mathrm{PS}$ and the epitopic changes associated with the presence of $\mathrm{N}$-acetyl-perosamine and absence of $\mathrm{N}$-formylperosamine in the O-PS (Additional file 3).

\section{Residual virulence and protection in mice}

These studies showed that the three vaccine candidates have attenuated virulence profiles with respect to their virulent counterparts (Figure 1). Bov::CA $\Delta$ wadB (Figure 1A) showed significantly lower CFU/spleen numbers than $B$. ovis PA virulent strains at weeks 3 (expected peak of multiplication for B. ovis) and 8 after inoculation. Attenuation with respect to the parental strain was clearly observed also for Rev1:: wbdR $\Delta w b k C$ (Figure 1B, from [19]) at post-inoculation weeks 1 (peak of multiplication for $B$. melitensis) and 5 . H38 $\Delta w b k F$ (Figure 1C) yielded similar CFU/spleen numbers to the parental strain at week 1 , but the mutant attenuation was evident at later stages (week 5).

Using this model, we tested all vaccine candidates for protection against $B$. ovis in two successive experiments. As can be seen in Table 2, the results obtained with all vaccine candidates were not statistically different from those obtained with the Rev 1 vaccine.

\section{Protection in rams}

No relevant clinical signs were evidenced after vaccination. The mean rectal temperature remained normal in the animals inoculated with the three vaccine candidates. Some Rev 1 vaccinated rams showed a slight increase in body temperature and an inflammatory reaction at the inoculation site that was resolved in a few weeks. Upon challenge, no vaccinated ram developed clinical testicular lesions but these were observed in two unvaccinated rams.

Table 1 Vaccine candidates.

\begin{tabular}{|c|c|c|c|}
\hline Vaccine & Genetic characteristics & Relevant phenotype & References \\
\hline Rev1::wbdR $\triangle w b k C$ & $\begin{array}{l}\text { Rev } 1 \text { wbkC (formyl-transferase gene) deleted mutant } \\
\text { carrying a mini-Tn7 insert with E. coli O157:H7 wbdR } \\
\text { (acetyl-transferase) }\end{array}$ & S-LPS with N-acetyl-perosamine O-PS & {$[19]$} \\
\hline $\mathrm{H} 38 \triangle w b k F$ & $\begin{array}{l}\text { B. melitensis } \mathrm{H} 38 \text { wbkF (bactoprenol priming for O-PS } \\
\text { polymerization gene) deleted mutant }\end{array}$ & R-LPS with intact core oligosaccharide & This work \\
\hline Bov::CA $\triangle$ wadB & $\begin{array}{l}\text { B. ovis PA wadB (core sugar glycosyl transferase gene) } \\
\text { deleted mutant carrying a mini-Tn7 insert with the } \\
\text { carbonic anhydrases (CAl and CAll) genes of B. abortus } \\
2308 \text { W }\end{array}$ & $\begin{array}{l}\mathrm{CO}_{2} \text {-independent; R-LPS with a trun- } \\
\text { cated core oligosaccharide }\end{array}$ & $\begin{array}{l}\text { This work. } \triangle \text { wadB and::CA } \\
\text { single mutants in [27] and [30], } \\
\text { respectively }\end{array}$ \\
\hline
\end{tabular}




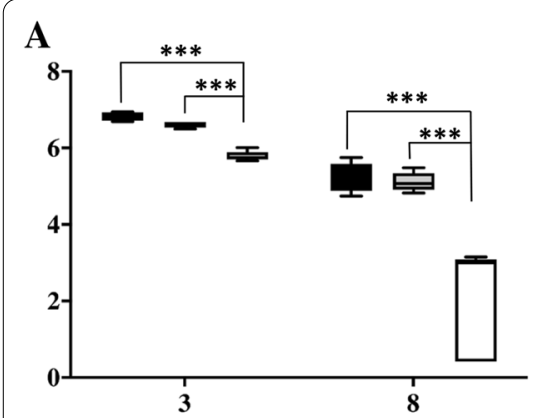

Weeks post-infection
B

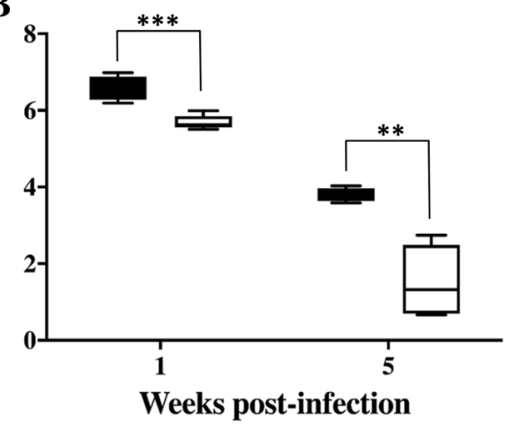

$\operatorname{Rev1}\left(10^{5}\right)$

Rev1::wbdR $\triangle w b k C\left(10^{8}\right)$
C

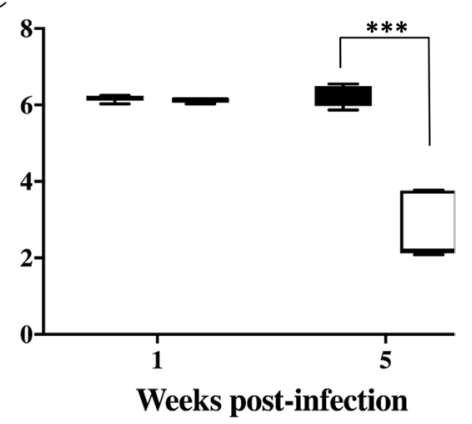

$\mathrm{H} 38 \mathrm{WT}\left(10^{4}\right)$

$\mathrm{H} 38 \Delta w b k F\left(10^{8}\right)$

Figure 1 Multiplication profiles in mice of the vaccine candidates Bov::CA $\Delta w a d B(A), \operatorname{Rev1}:: w b d R \Delta w b k C(B, \operatorname{taken}$ from [19]) and $\mathbf{H} 38 \Delta \boldsymbol{w b k F}(\mathbf{C})$ with respect to their corresponding parental strains. Mice were inoculated intraperitoneally with the doses (CFU/mouse) indicated in brackets for each strain. Significant differences: ${ }^{* *}=p<0.01,{ }^{* *}=p<00.001$.

Table 2 Protection against B. ovis PA- $\mathrm{Km}^{\mathrm{R}}$ in mice.

\begin{tabular}{|c|c|c|c|}
\hline Experiment & Vaccine (CFU dose) & $\begin{array}{l}\text { B. ovis PA-Km }{ }^{R} \\
\text { (mean } \pm \mathrm{SD} \text { of } \log _{10} \\
\text { CFU/spleen) }\end{array}$ & $\begin{array}{l}\text { Units of } \\
\text { protection }^{\mathrm{a}}\end{array}$ \\
\hline \multirow[t]{4}{*}{1} & Bov::CA $\triangle$ wadB $\left(10^{8}\right)$ & $2.46 \pm 1.68^{b, c}$ & 3.6 \\
\hline & $\mathrm{H} 38 \Delta w b k F\left(10^{8}\right)$ & $3.42 \pm 0.62^{b, c}$ & 2.6 \\
\hline & Rev $1\left(10^{5}\right)$ & $2.50 \pm 1.49^{b}$ & 3.5 \\
\hline & Placebo (BSS) & $6.04 \pm 0.46$ & 0 \\
\hline \multirow[t]{3}{*}{2} & $\begin{array}{l}\text { Rev } 1:: w b d R \Delta w b k C \\
\left(10^{8}\right)\end{array}$ & $2.16 \pm 0.95^{b, c}$ & 4.1 \\
\hline & $\operatorname{Rev} 1\left(10^{5}\right)$ & $2.45 \pm 1.35^{b}$ & 3.8 \\
\hline & Placebo (BSS) & $6.26 \pm 0.16$ & 0 \\
\hline
\end{tabular}

${ }^{a}$ Units of protection: average $\log _{10}$ CFU of challenge strain in the spleens of placebo (BSS) controls minus average of $\log _{10} \mathrm{CFU}$ of the challenge strain in the spleens of vaccinated mice. ${ }^{b}$ Significant differences $(P<0.01)$ versus the placebo (BSS) control group (ANOVA and Fisher's PSLD test); ${ }^{C}$ No significant differences versus the Rev 1 vaccinated group (ANOVA and Fisher's PSLD test).
The results of the thorough bacteriological search after necropsy are summarized in Table 3 and Figure 2. Taken together, the results of control groups show that the experimental conditions resulted in values suitable for statistical comparisons $(84.6 \%$ vs. $21.4 \%$ infected rams in the unvaccinated and Rev 1 vaccinated groups, respectively; $P<0.05)$. The protection conferred by Bov::CA $\Delta$ wadB was manifestly not significant (78.6\% of infections) and that of the Rev1::wbdR $\Delta w b k C$ candidate (50\% of infections) not statistically different from that of the unvaccinated control group. On the other hand, $\mathrm{H} 38 \Delta w b k F$ conferred a level of protection (16.7\% of infections) similar to that obtained with Rev 1 (Table 3), with slightly lower percentages of infected organs and no isolation from cranial, scrotal or prefemoral lymph nodes (Figure 2). These results were paralleled in the numbers of infected organs (Table 3) (5.4\% and $10.7 \%$ for $\mathrm{H} 38 \Delta w b k F$ and Rev 1, respectively) and of severely infected animals/organs $(7.1 \% / 1.8 \%$ and $7.1 \% / 0.9 \%$ for $\mathrm{H} 38 \Delta w b k F$ and Rev 1 , respectively).

Table 3 Protective efficacy of vaccine candidates against a $B$. ovis PA experimental challenge in rams.

\begin{tabular}{|c|c|c|c|}
\hline Vaccine (CFU dose) & $\begin{array}{l}\text { No. infected animals/total } \\
(\%)^{\mathrm{a}}\end{array}$ & $\begin{array}{l}\text { No. infected organs/total } \\
(\%)^{\mathrm{b}}\end{array}$ & $\begin{array}{l}\text { No. severely infected animals } \\
(\%)^{\mathrm{a}, c} / \text { no. severely infected organs } \\
(\%)^{\mathrm{b}}\end{array}$ \\
\hline Bov::CA $\triangle$ wadB $\left(1 \times 10^{10}\right)$ & $11 / 14(78.6)$ & $41 / 112(36.6)$ & $4(28.6)^{d} / 11(9.8)^{d}$ \\
\hline 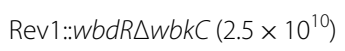 & $7 / 14(50.0)$ & $30 / 112(26.8)^{d}$ & $5(35.7) / 13(11.6)^{d}$ \\
\hline $\mathrm{H} 38 \Delta \mathrm{wbkF}\left(2.5 \times 10^{10}\right)$ & $2 / 14(16.7)^{e, f}$ & $6 / 112(5.4)^{e, f}$ & $1(7.1)^{e, f} / 2(1.8)^{e, f}$ \\
\hline $\operatorname{Rev} 1\left(2 \times 10^{9}\right)$ & $3 / 14(21.4)^{d}$ & $12 / 112(10.7)^{\mathrm{e}}$ & $1(7.1)^{\mathrm{e}} / 1(0.9)^{\mathrm{e}}$ \\
\hline Unvaccinated & $11 / 13(84.6)$ & $64 / 104(61.5)$ & $9(69.2) / 30(28.8)$ \\
\hline
\end{tabular}

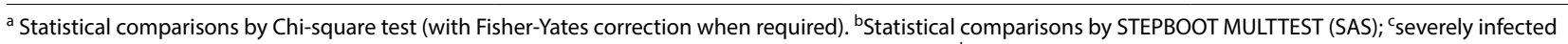
animals were those showing at least one organ sample with an infection level $\geq 3$ ( $\geq 26 \mathrm{CFU} /$ plate). ${ }^{\mathrm{d}}$ Significant difference ( $P<0.05$ ) versus unvaccinated control; ${ }^{\mathrm{e}} \mathrm{High}$ significant difference $(P<0.001)$ vs. unvaccinated control; ${ }^{f}$ no significant $(P>0.05)$ versus Rev 1 vaccinated group. 


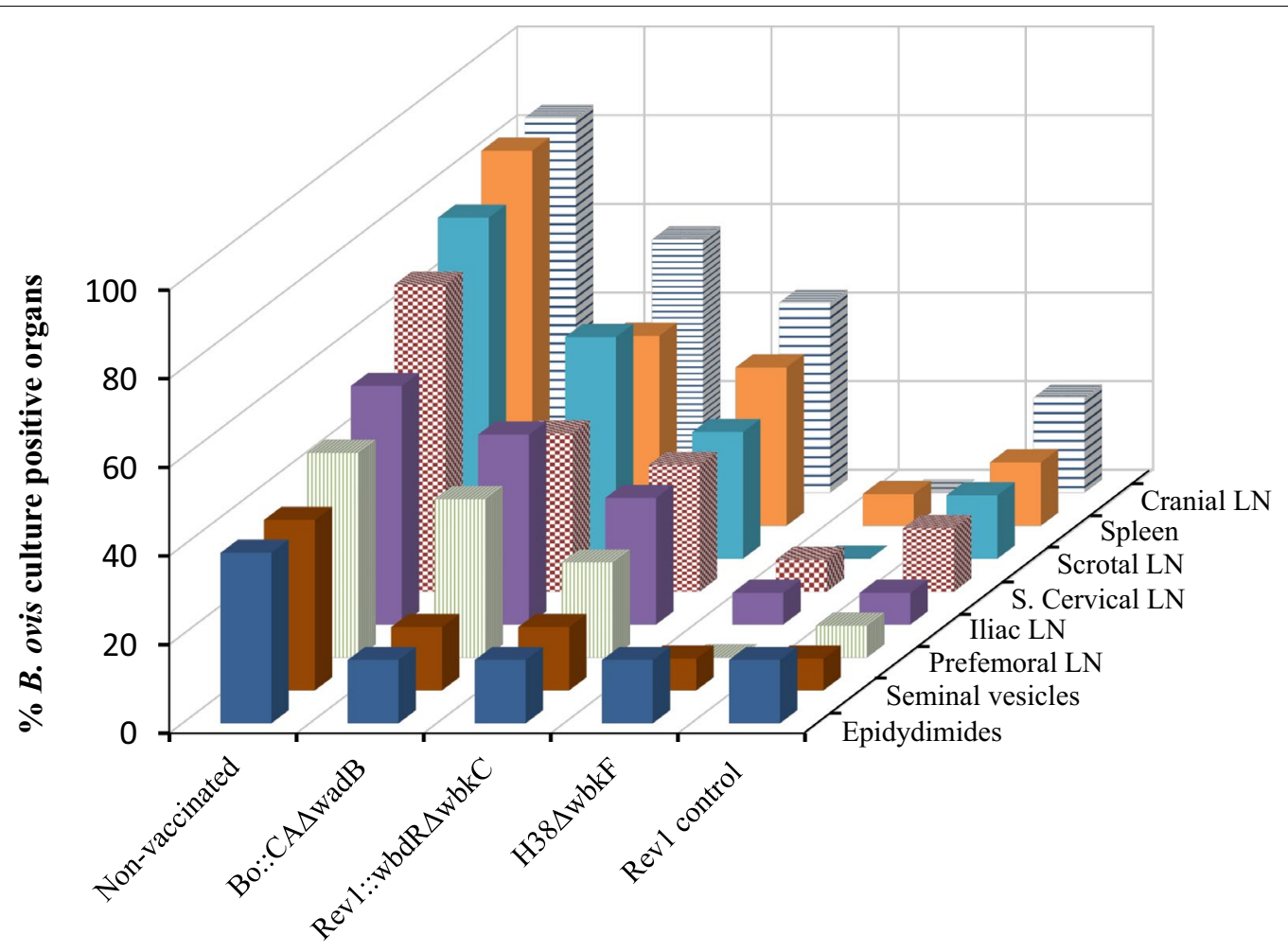

Figure 2 Percentages of $B$. ovis culture positive organs in each experimental group of vaccinated rams.

\section{Serological responses in rams}

Figure 3 presents the results of the antibody response to the $B$. ovis HS envelope antigens generated in vaccinated rams before and after challenge. All rams were positive in the AGID assay by week 1 after immunization, with the notable exception of those vaccinated with Bov::CA $\triangle w a d B$ among which very few positive responses were detected before challenge (Figure 3A). In the Rev1::wbdR $\Delta w b k C$ and Rev 1 vaccinated groups, AGID-positive responses decreased rapidly and all animals became negative by weeks 10 and 23, respectively (Figure 3A). As judged by the percentage of AGIDpositive animals, $\mathrm{H} 38 \Delta w b k F$ elicited the most durable antibody response, with over $60 \%$ of positive animals until week 17 (Figure 3A). No matter the experimental group, all rams were AGID-negative before challenge (week 33). When assessed by iELISA (Figure 3B), the percentage of positive animals in the groups vaccinated with Bov::CA $\Delta w a d B$ and $\mathrm{H} 38 \Delta w b k F$ were higher and more persistent than those observed in the AGID test

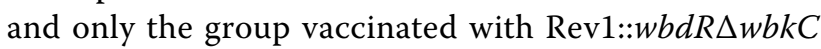
was totally negative by the time of challenge. Interestingly, when sera from Bov::CA $\triangle$ wadB vaccinated rams were studied in the iELISA with a homologous HS antigen, $100 \%$ of them were positive from week 1 until the end of the experiment (not shown). Upon challenge, most animals became both AGID and HS iELISA-positive, as expected.

Figure 4 presents the results obtained with serodiagnostic tests for $\mathrm{S}$ brucellae. Unsurprisingly, all animals vaccinated with Rev 1 were positive in RBT, CFT and S-LPS iELISA by week 2 and a high percentage remained positive thereafter. Although Rev1::wbdR $\Delta w b k C$ bears a modified O-PS, all rams vaccinated with this candidate were positive in both RBT and CFT during the first weeks but the reactions persisted less than those induced by Rev 1. However, only very few and transient reactions were detected in the S-LPS iELISA in these Rev1::wbdR $\Delta w b k C$ vaccinated rams (Figure $4 C$ ), even though these rams showed a more intense and persistently positive response in the $w b d R \Delta w b k C$ iELISA (Additional file 4). In contrast with Rev 1 and Rev1::wbdR $\Delta w b k C$ vaccinates, no ram immunized with $\mathrm{H} 38 \Delta w b k F$ or Bov::CA $\Delta w a d B$ showed antibodies detectable in either RBT or CFT, and only a few of those vaccinated with $\mathrm{H} 38 \Delta w b k F$ showed a transiently positive and relatively early response in the S-LPS iELISA before challenge (Figure 4). As expected, the proportion of RBT and CFT positive animals did not increase after the challenge for any of the experimental groups (Figures $4 \mathrm{~A}$ and B) but $50 \%$ and less than 20\%, respectively, of $\mathrm{H} 38 \Delta w b k F$ and Bov::CA $\Delta w a d B$ vaccinated rams reacted then in the S-LPS iELISA (Figure $4 C$ ). 


\section{A. AGID}

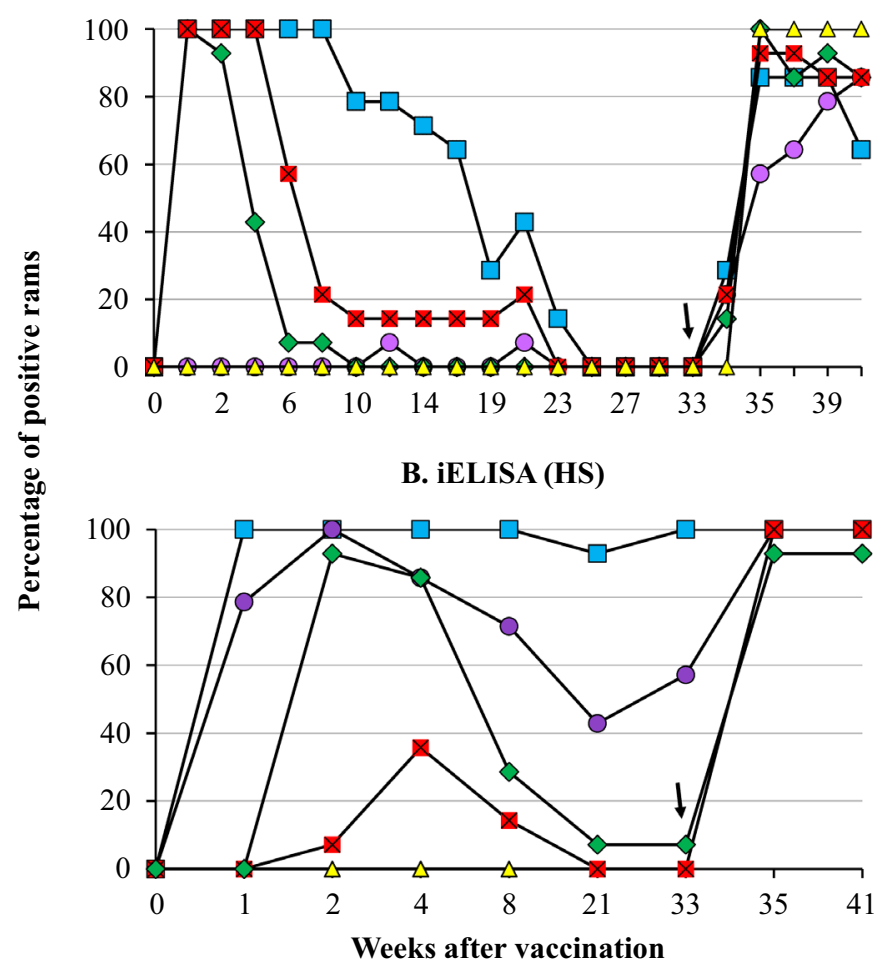

$-\star-\operatorname{Rev} 1$ control

$\prec \operatorname{Rev} 1:: w b d R \Delta w b k C$

$-\square-\mathrm{H} 38 \Delta w b k F$

$\multimap-$ Bov::CA $\Delta w a d B$

$\neg-$ Unvaccinated control

$\downarrow$ BoPA Challenge

Figure 3 Evolution of the percentages of positive rams after vaccination (week 0) and challenge (week 33) in: (A) AGID; and (B) iELISA using B. ovis HS extracts.

\section{Discussion}

As underlined in the Introduction, there is a need for a $B$. ovis vaccine to replace $\operatorname{Rev} 1$, banned in areas where $B$. melitensis has been eradicated or has never been present. Following the evidence that live-attenuated vaccines are advantageous for triggering protective responses against Brucella [47], in this work we investigated three vaccine candidates of this kind.

It is known that Brucella behaves as a stealthy parasite that avoids detection by innate immunity at the onset of infection, thus retarding the adaptive response and facilitating to reach intracellular niches [48]. This furtive behavior is related to the absence of marked pathogenassociated molecular patterns in envelope molecules, chiefly in the LPS [48]. Immunological, genetic and structural investigations have established that the core of Brucella LPS carries a pentasaccharide branch that hinders recognition of the lipid A-inner core by the TLR4MD2 receptor system of innate immunity [27, 36, 49, 50]. Hence, mutations preventing the assembly of this pentasaccharide bolster Th1 immunoresponses, thereby causing attenuation $[27,36,49,50]$. Consequently, disruption of the core lateral branch was proposed as a strategy to develop brucellosis vaccines [51] and previous work with $B$. ovis shows that the core glycosyltransferase gene $w a d B$ is an appropriate target for this purpose [27]. Yet, we found that, when combined with CA genes of $B$. abortus to overcome the practical limitations of $\mathrm{CO}_{2}$-dependence, the $B$. ovis wadB mutant was totally ineffective as vaccine in rams even though it was protective in mice. These results mean that the mouse model failed utterly to predict a positive vaccine result in the natural host, and are in line with other data that strongly suggest that its usefulness in the search for a brucellosis live vaccine is limited to screen out overattenuated or none protective candidates [32, 33, 52, 53].

Nevertheless, the total failure of Bov::CA $\triangle w a d B$ as a vaccine was unexpected and, although the explanation is far from obvious, it is worthwhile to speculate on the reasons. Noteworthy, proportions of Bov::CA $\triangle w a d B$ vaccinated rams positive in AGID and iELISA with $B$. ovis HS were respectively lower than those in any other vaccinated group. Since all rams remained positive in the iELISA with HS of the homologous Bov::CA $\triangle w a d B$, and HS is rich in R-LPS [46], these results evidence the importance of the epitopes of the core branch in the antibody response to $B$. ovis LPS. In mice, a role for antibodies in $B$. ovis protective immunity has been shown in passive 
A. RBT

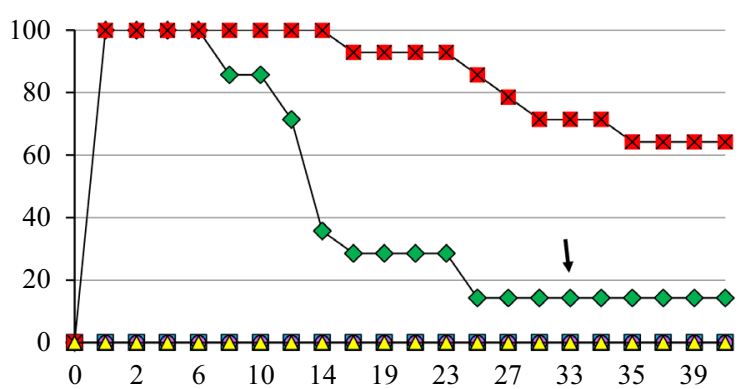

C. iELISA (S-LPS)

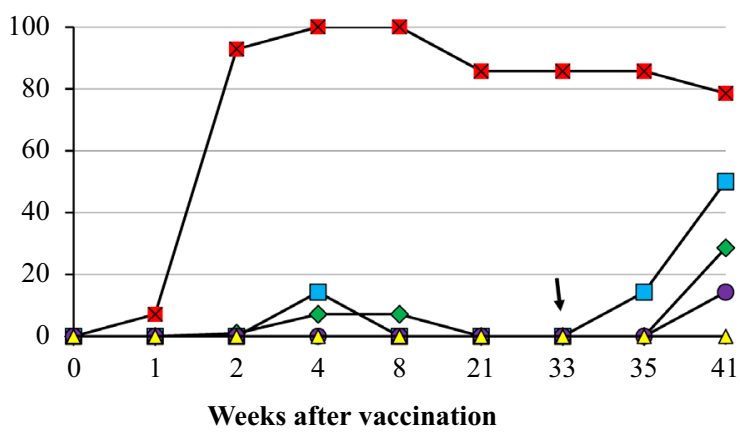

B. CFT

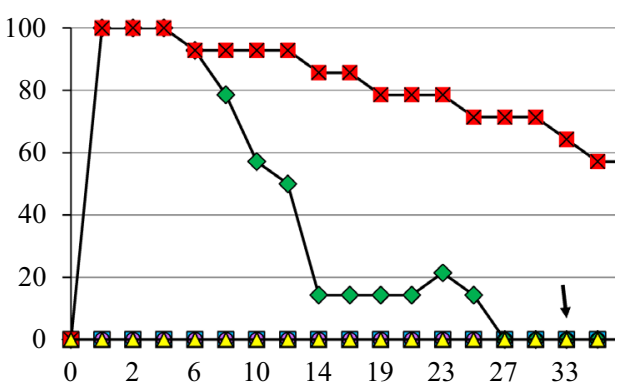

$\rightarrow-\operatorname{Rev} 1$ control

$\prec \operatorname{Rev} 1:: w b d R \Delta w b k C$

$-\square-\mathrm{H} 38 \Delta w b k F$

$-O-$ Bov::CA $\Delta w a d B$

$-\triangle$ Unvaccinated control

$\downarrow$ BoPA Challenge

Figure 4 Evolution of the percentages of positive rams in S-LPS tests after vaccination (week 0) and challenge (week 33): (A) RBT; (B), CFT; and (C) iELISA.

transfer assays with monoclonal antibodies to envelope antigens and with sera from mice immunized with RB51 (reviewed in [35]). However, vaccination with HS in sheep does not show a correlation between protection and the intensity of the antibody response to these antigens $[20,35]$. On the other hand, experiments with the same antigens in several adjuvant formulations provide clear evidence that a strong Th1 cell-mediated immunoresponse is important in protection in sheep [21,35].

Therefore, although the lack of antibodies to the full core may play a role, we favor the hypothesis that the failure of Bov::CA $\Delta w a d B$ to protect against $B$. ovis was caused by an inappropriate Th1 response. This may seem paradoxical because the LPS core defect has been shown to increase recognition by LPS receptors (see above), thereby bolstering pro-inflammatory cytokine production and initiating the Th1 response at earlier times than the wild- type [49]. However, this comparatively early Th1 response accelerates clearance of Brucella core mutants in mice [49] and, as discussed below, a given permanence in the host is necessary for a vaccine to generate protective immunity. Thus, it could be that Bov::CA $\Delta w a d B$ clearance was too rapid to generate such a response. Investigation of these hypotheses could help to clarify the virulence mechanisms of $B$. ovis and the immunity to this comparatively less studied species, knowledge with which it may be possible to develop an homologous $B$. ovis vaccine.

We also examined the Rev1::wbdR $\Delta w b k C$ construct. Based on the results in mice [19], the premises were that this candidate could protect sheep against $B$. ovis and elicit antibodies that, while not interfering in standard S-LPS tests, could be useful to identify vaccinated animals. Concerning protection, we found that it was insufficient, even though in this case the differences with the results in mice were not as dramatic as those of Bov::CA $\triangle w a d B$. It is worth pointing out that since the first studies with vaccine RB51 a much larger dose has been found necessary to show that some R mutants match the protection obtained with S19 or Rev 1 (reference OIE $S$ vaccines) in mice [16, 32, 52, 53], and this is also true for Rev1::wbdR $\Delta w b k C$ (Table 2 and [19]). However, to reproduce in the natural host the $3 \log$ dose increase applied in the mouse model is not feasible (doses over $10^{10} \mathrm{CFU}$ are not practical in sheep). Therefore, we used a dose equivalent to that of $\mathrm{R}$ vaccines $\left(1-5 \times 10^{10}\right.$, [33]). Thus, the contrasting results obtained with Rev1:: $w b d R \Delta w b k C$ in rams and in mice are likely to reflect the laboratory bias in dose introduced for screening purposes and the limitations of the mouse model.

Why Rev1::wbdR $\Delta w b k C$ being smooth could require a dose larger than Rev 1 in the mouse model may reflect 
a defect in cell entry and/or control of intracellular trafficking caused by the O-PS modification because both are critical processes in the biology of S Brucella in which the wild-type O-PS plays an important role [54, 55]. Concerning the specificity of the antibodies, our results show that the change in O-PS epitopic structure

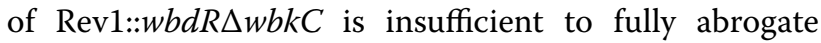
the interference in standard S-LPS tests (Figure 4) or to differentiate vaccinated and infected rams (Additional file 4). These results, which are reminiscent of the reactivity of IgG of infected cattle with the O-PS of the E. hermanii serotypes that carry $\mathrm{N}$-acetyl-perosamine [56] set another difference with the mouse model [19] and discourage a practical use of this vaccine epitopic tagging.

In contrast with the other candidates, $\mathrm{H} 38 \Delta w b k F$ generated protection in rams similar to that obtained with reference Rev 1 vaccine. In previous works, we found that an intact LPS core is necessary for an $\mathrm{R}$ vaccine to provide maximal protection in at least the mouse model, and $w b k F$ mutants meet this requisite [16, 32]. Also in keeping with the predicted function of WbkF (Table 1), they are unable to synthesize internal O-PS precursors that would elicit anti-O-PS antibodies, an undesirable effect in an $R$ vaccine that occurs in $w a d A$ (formerly $w a^{* * *}$ ) and $w z m \mathrm{R}$ mutants [32, 33, 57, 58]. Moreover, as indicated in the Introduction, this candidate was not selected only by the results in mice. In a previous work [33], we found that a B. melitensis $\mathrm{H} 38 w b k F:: \operatorname{Tn} 5 \mathrm{Km}^{\mathrm{R}}$ mutant had an organ distribution and persistence in sheep like those of Rev 1, strongly suggesting similarly intense antigenic stimuli. All these characteristics made strain H38 and gene $w b k F$ attractive for developing a $B$. ovis vaccine, and for a potential use we constructed the mutant by deletion (to avoid any potential reversibility) without antibioticresistance markers. Thus, although we did not evaluate again the kinetics of infection of the $\mathrm{H} 38 \Delta w b k F$ mutant in rams, its almost total identity with the H38wbkF::Tn5 $\mathrm{Km}^{\mathrm{R}}$ should result in a distribution and persistence similar to that of Rev 1 and, in fact, both elicited similarly persistent positive responses in the B. ovis HS-AGID.

As predicted, vaccination with $\mathrm{H} 38 \Delta w b k F$ did not generate a serological interference in either RBT or CFT, tests that detect anti-O-PS antibodies [3]. However, transient reactions were observed in the S-LPS ELISA, and the interference in this assay (but not in the RBT and CFT) was evident after challenge. This was not unexpected since $\mathrm{R}$ vaccines and B. ovis induce antibodies to the core epitopes shared by the R and S-LPS that, while not accessible in tests like RBT and CFT, become exposed to antibodies in ELISA and in the fluorescence polarization assay [3]. Therefore, if $\mathrm{H} 38 \Delta w b k F$ (or any other $\mathrm{R}$ vaccine) is employed in $B$. melitensis-free areas where the latter two tests are used for surveillance, this cross-reactivity should be considered and the simple and inexpensive RBT implemented as a parallel test in doubtful cases. A more difficult practical problem is posed by the interference of $\mathrm{H} 38 \Delta w b k F$ in $B$. ovis serodiagnostic tests. Although more persistent in iELISA than in AGID, in which all animals were negative 27 weeks after vaccination (Figure 3), this is a protracted response that may hamper implementation of test and slaughter combined with $\mathrm{H} 38 \Delta w b k F$ vaccination for the eradication of $B$. ovis infection. More information is necessary to better assess the effects of route of vaccination, vaccine dose and the optimal age of sheep at vaccination on this diagnostic interference, as well as the efficacy of the H38 $w b k F$ vaccine under field conditions and the potential effects that anamnestic responses after contacts with $B$. ovis field strains may have in vaccinated animals. Given the importance of ewes in the epidemiology of B. ovis [10], the vaccination of female sheep would be essential to a suitable control of infection. Like Rev 1, at least the B. melitensis B115 spontaneous wzm $\mathrm{R}$ mutant is highly abortifacient in pregnant sheep [58] and this and other potential untoward effects of the $\mathrm{H} 38 \Delta w b k F$ vaccine in adult sheep need to be investigated. Research is in progress to further define the conditions of field use of $\mathrm{H} 38 \Delta w b k F$.

\section{Supplementary Information}

The online version contains supplementary material available at https://doi. org/10.1186/s13567-022-01034-z.

Additional file 1: Primers used for mutant construction

Additional file 2: $E$. coli S17 $\lambda$ pir and plasmids used for mutant construction

Additional file 3: LPS characterization of vaccine candidates by SDSPAGE electrophoresis-silver staining and Western blot analyses of SDS-proteinase K extracts. Upper panels (from [19]): Analyses of (1) Rev 1, (2) Rev1::Tn7wbdR, and (3) Rev1::Tn7wbdR $\Delta$ wbkC extracts. Lower panels: Analyses of (4) H38, (5) H38 $\Delta w b k F$, (6) Bov::CA and (7) Bov::CA $\triangle$ wadB extracts.

Additional file 4: Reactivity (\%OD) in iELISA using N-formyl-perosamine wild-type S-LPS (A) or $\mathrm{N}$-acetyl-perosamine S-LPS from a $w b d R \Delta w b k C$ construct (B) and 46 sera from $B$. melitensis culture positive $(C+)$ sheep, 78 brucellosis-free $(B F)$ sheep and rams immunized with Rev1::wbdRAwbkC.

\section{Acknowledgements}

S. Serrano, M. Uriarte and P. Hijazo for their excellent technical assistance in the laboratory, F. Jaso and I. Escota for taking care of the animals and J.L. Alabart for the statistical advice.

\section{Authors' contributions}

PMM, RC-A, IM and JMB conceived and coordinated the study. MI supervised the genomic studies. AZ-R, BA-A, MS-B and EM-G participated in the mutant construction and characterization. NV contributed to preliminary experiments in laboratory models. MJM, SA-B, MB and PMM conducted the experiments in mice and rams. PM, JMB, RC-A and IM wrote the manuscript. All authors read and approved the final version of the manuscript. 


\section{Funding}

This research was mainly supported by the project grant AGL2014-58795C4-1/3/4-R (MINECO/AEI/FEDER) and partially by the Aragon Government (Grupo de Investigación A13_17R and A21_20R), ISTUN -Institute of Tropical Health funders (Fundación la CAIXA -LCF/PR/PR13/11080005and Fundación Caja Navarra, Fundación María Francisca de Roviralta, Ubesol and Inversiones Garcilaso de la Vega S.L). Part of this work also integrates into project PID2019-107601RB-C31 financed by MCIN/AEI/ 10.1303910.13039/501100011033. B. Aragón-Aranda was recipient of the PhD fellowship BES-2015-075609 (MINECO).

\section{Declarations}

\section{Ethics approval and consent to participate}

Procedures in mice and rams were performed in accordance with the current European (directive 86/609/EEC) and Spanish (RD 53/2013) legislations, supervised by the corresponding Ethical Committee for Animal Experimentation and authorized by the Aragón (reports No. 2014-20, 2014-21 and 2014-24) and Navarra (CEEA 045/12) Governments.

\section{Competing interests}

The authors declare that they have no competing interests.

\section{Author details}

'Departamento de Ciencia Animal, Centro de Investigación y Tecnología Agroalimentaria de Aragón (CITA), Zaragoza, Spain. Instituto Agroalimentario de Aragón-IA2 (CITA-Universidad de Zaragoza), Zaragoza, Spain. ${ }^{3}$ Instituto de Salud Tropical, Instituto de Investigación Sanitaria de Navarra and Departamento de Microbiología y Parasitología, Universidad de Navarra, Pamplona, Spain. ${ }^{4}$ Otology and Neurotology Group CTS495, Department of Genomic Medicine, GENYO Centre for Genomics and Oncological Research, PfizerUniversity of Granada-Junta de Andalucía, Granada, Spain. ${ }^{5}$ Departamento de Patología Animal, Universidad de Zaragoza, Zaragoza, Spain. ${ }^{6}$ Departamento de Microbiología y Genética, Universidad de Salamanca, Salamanca, Spain.

Received: 9 December 2021 Accepted: 20 January 2022

Published online: 02 March 2022

\section{References}

1. McDermott J, Grace D, Zinsstag J (2013) Economics of brucellosis impact and control in low-income countries. Rev Sci Tech 32:249-261. https:// doi.org/10.20506/rst.32.1.2197

2. Moreno E (2020) The one hundred year journey of the genus Brucella (Meyer and Shaw 1920). FEMS Microbiol Rev 45:fuaa045. https://doi.org/ 10.1093/femsre/fuaa045

3. Ducrotoy MJ, Conde-Álvarez R, Blasco JM, Moriyón I (2016) A review of the basis of the immunological diagnosis of ruminant brucellosis. Vet Immunol Immunopathol 171:81-102. https://doi.org/10.1016/j.vetimm. 2016.02.002

4. Zygmunt MS, Blasco JM, Letesson JJ, Cloeckaert A, Moriyón I (2009) DNA polymorphism analysis of Brucella lipopolysaccharide genes reveals marked differences in O-polysaccharide biosynthetic genes between smooth and rough Brucella species and novel species-specific markers. BMC Microbiol 9:92. https://doi.org/10.1186/1471-2180-9-92

5. Tsolis RM, Seshadri R, Santos RL, Sangari FJ, Lobo JM, de Jong MF, Ren Q Myers G, Brinkac LM, Nelson WC, Deboy RT, Angiuoli S, Khouri H, Dimitrov G, Robinson JR, Mulligan S, Walker RL, Elzer PE, Hassan KA, Paulsen IT (2009) Genome degradation in Brucella ovis corresponds with narrowing of its host range and tissue tropism. PLoS One 4:e5519. https://doi.org/10. 1371/journal.pone.0005519

6. Picard-Hagen N, Berthelot X, Champion JL, Eon L, Lyazrhi F, Marois M, Peglion M, Schuster A, Trouche C, Garin-Bastuji B (2015) Contagious epididymitis due to Brucella ovis: relationship between sexual function, serology and bacterial shedding in semen. BMC Vet Res 11:125. https:// doi.org/10.1186/s12917-015-0440-7

7. ECDC (2019) European Centre for Disease Prevention and Control. Brucellosis. In: ECDC. Annual epidemiological report for 2017. Stockholm,
Sweden. https://www.ecdc.europa.eu/sites/default/files/documents/ brucellosis-annual-epidemiological-report-2017.pdf.

8. Moreno E (2014) Retrospective and prospective perspectives on zoonotic brucellosis. Front Microbiol 5:213. https://doi.org/10.3389/fmicb.2014. 00213

9. Marco J, González L, Cuervo LA, De Heredia FB, Barberán M, Marín C, Blasco JM (1994) Brucella ovis infection in two flocks of sheep. Vet Rec 135:254-256. https://doi.org/10.1136/vr.135.11.254

10. Blasco JM (2010) Brucella Ovis Infection. In: Lefèvre PC, Blancou JC, Chermette R, Uilenberg G (eds) Infectious and parasitic diseases of livestock, vol 2. Lavoisier. Paris, France, pp 1047-1063

11. Ridler AL, West DM (2011) Control of Brucella ovis infection in sheep. Vet Clin North Am Food Anim Pract 27:61-66. https://doi.org/10.1016/j.cvfa. 2010.10.013

12. Blasco JM (1990) Brucella ovis. In: Neilsen K, Duncan JR (eds) Animal Brucellosis. CRC Press, Boca Raton, pp 351-378

13. Marín CM, Mainar RC, de Miguel MJ, Andrés-Barranco S, Álvarez JJ, Blasco JM, Muñoz PM (2019) Re-emergence of Brucella ovis infection in Aragón (Spain) after the ban of Rev 1 vaccination In: International Brucellosis Society Meeting, Chicago, EEUU. https://citarea.cita-aragon.es/citarea/ bitstream/10532/4864/1/2019_420ab.pdf

14. El Idrissi AH, Benkirane A, El Maadoudi M, Bouslikhane M, Berrada J, Zerouali A (2001) Comparison of the efficacy of Brucella abortus strain RB51 and Brucella melitensis Rev 1 live vaccines against experimental infection with Brucella melitensis in pregnant ewes. Rev Sci Tech 20:741-747. https://doi.org/10.20506/rst.20.3.1305

15. Jiménez de Bagüés MP, Barberán M, Marín CM, Blasco JM (1995) The Brucella abortus RB51 vaccine does not confer protection against Brucella ovis in rams. Vaccine 13:301-304. https://doi.org/10.1016/0264-410x(95) 93317-3

16. Monreal D, Grilló MJ, Gonzalez D, Marín CM, De Miguel MJ, Lopez-Goñi I, Blasco JM, Cloeckaert A, Moriyon I (2003) Characterization of Brucella abortus O-polysaccharide and core lipopolysaccharide mutants and demonstration that a complete core is required for rough vaccines to be efficient against Brucella abortus and Brucella ovis in the mouse model. Infect Immun 71:3261-3271. https://doi.org/10.1128/IAI.71.6.3261-3271. 2003

17. Grilló MJ, Marín CM, Barberan M, de Miguel MJ, Laroucau K, Jacques I, Blasco JM (2009) Efficacy of bp26 and bp26/omp31 B. melitensis Rev. 1 deletion mutants against Brucella ovis in rams. Vaccine 27:187-191. https://doi.org/10.1016/j.vaccine.2008.10.065

18. Zabalza-Barangua A, San Román B, Chacón-Díaz C, de Miguel MJ, Munoz PM, Iriarte M, Blasco JM, Grilló MJ (2018) GFP tagging of Brucella melitensis Rev1 allows the identification of vaccinated sheep. Transbound Emerg Dis 66:505-516. https://doi.org/10.1111/tbed.13053

19. Aragón-Aranda B, de Miguel MJ, Martínez-Gómez E, Zúñiga-Ripa A, Salvador-Bescós M, Moriyón I, Iriarte M, Muñoz PM, Conde-Álvarez R (2019) Rev 1 wbdR tagged vaccines against Brucella ovis. Vet Res 50:95. https://doi.org/10.1186/s13567-019-0714-3

20. Blasco JM, Gamazo C, Winter AJ, Jiménez de Bagüés MP, Marín C, Barberán M, Moriyón I, Alonso-Urmeneta B, Díaz R (1993) Evaluation of whole cell and subcellular vaccines against Brucella ovis in rams. Vet Immunol Immunopathol 37:257-270. https://doi.org/10.1016/01652427(93)90198-d

21. Da Costa MR, Irache JM, Blasco JM, Muñoz MP, Marín CM, Grilló MJ, De Miguel MJ, Barberán M, Gamazo C (2010) Evaluation of particulate acellular vaccines against Brucella ovis infection in rams. Vaccine 28:3038-3046. https://doi.org/10.1016/j.vaccine.2009.10.073

22. Díaz AG, Quinteros DA, Paolicchi FA, Rivero MA, Palma SD, Pardo RP, Clausse M, Zylberman V, Goldbaum FA, Estein SM (2019) Mucosal immunization with polymeric antigen BLSOmp31 using alternative delivery systems against Brucella ovis in rams. Vet Immunol Immunopathol 209:70-77. https://doi.org/10.1016/j.vetimm.2019.02.005

23. Estein SM, Fiorentino MA, Paolicchi FA, Clausse M, Manazza J, Cassataro J, Giambartolomei GH, Coria LM, Zylberman V, Fossati CA, Kjeken R, Goldbaum FA (2009) The polymeric antigen BLSOmp31 confers protection against Brucella ovis infection in rams. Vaccine 27:6704-6711. https://doi. org/10.1016/j.vaccine.2009.08.097 
24. Silva AP, Macedo AA, Costa LF, Rocha CE, García LN, Farias JR, Gomes PP, Teixeira GC, Fonseca KW, Maia AR, Neves GG, Romao EL, Silva TM, Mol JP, Oliveira RM, Araujo MS, Nascimento EF, Martins-Filho OA, Brandao HM, Paixao TA, Santos RL (2015) Encapsulated Brucella ovis lacking a putative ATP-binding cassette transporter (DeltaabcBA) protects against wild type Brucella ovis in Rams. PLoS One 10:e0136865. https://doi.org/10.1371/ journal.pone.0136865

25. Silva AP, Macedo AA, Silva TM, Ximenes LC, Brandao HM, Paixao TA, Santos RL (2015) Protection of an encapsulated live attenuated strain of Brucella ovis (DeltaabcBA) against experimental challenge in the murine model. Clin Vaccine Immunol 22:789-797. https://doi.org/10.1128/cvi.00191-15

26. Grilló MJ, Marín CM, Barberán M, Blasco JM (1999) Experimental Brucella ovis infection in pregnant ewes. Vet Rec 144:555-558. https://doi.org/10 1136/vr.144.20.555

27. Soler-LLorens $P$, Gil-Ramírez $Y$, Zabalza-Barangua A, Iriarte M, Conde $R$, Zúñiga-Ripa A, San Román B, Zygmunt M, Vizcaíno N, Cloeckaert A, Grilló M-J, Moriyón I, Lopez-Goñi I (2014) Mutants in the lipopolysaccharide of Brucella ovis are attenuated and protect against $B$. ovis infection in mice. Vet Res 45:72. https://doi.org/10.1186/s13567-014-0072-0

28. Sancho P, Tejedor C, Sidhu-Muñoz RS, Fernández-Lago L, Vizcaíno N (2014) Evaluation in mice of Brucella ovis attenuated mutants for use as live vaccines against B. ovis infection. Vet Res 45:61. https://doi.org/10. 1186/1297-9716-45-61

29. Sidhu-Muñoz RS, Sancho P, Cloeckaert A, Zygmunt MS, de Miguel MJ, Tejedor C, Vizcaíno N (2018) Characterization of cell envelope multiple mutants of Brucella ovis and assessment in mice of their vaccine potential. Front Microbiol 9:2230. https://doi.org/10.3389/fmicb.2018.02230

30. Vizcaíno N, Pérez-Etayo L, Conde-Álvarez R, Iriarte M, Moriyón I, ZúñigaRipa A (2020) Disruption of pyruvate phosphate dikinase in Brucella ovis $\mathrm{PA} \mathrm{CO}_{2}$-dependent and independent strains generates attenuation in the mouse model. Vet Res 51:101. https://doi.org/10.1186/ s13567-020-00824-7

31. Pérez-Etayo L, de Miguel MJ, Conde-Álvarez R, Muñoz PM, Khames M, Iriarte M, Moriyón I, Zúñiga-Ripa A (2018) The $\mathrm{CO}_{2}$-dependence of Brucella ovis and Brucella abortus biovars is caused by defective carbonic anhydrases. Vet Res 49:85. https://doi.org/10.1186/s13567-018-0583-1

32. González D, Grilló MJ, De Miguel MJ, Ali T, Arce-Gorvel V, Delrue RM, Conde-Álvarez R, Muñoz P, López-Goñi I, Iriarte M, Marín CM, Weintraub A, Widmalm G, Zygmunt M, Letesson JJ, Gorvel JP, Blasco JM, Moriyón I (2008) Brucellosis vaccines: assessment of Brucella melitensis lipopolysaccharide rough mutants defective in core and O-polysaccharide synthesis and export. PLoS One 3:e2760. https://doi.org/10.1371/journal.pone. 0002760

33. Barrio MB, Grilló MJ, Muñoz PM, Jacques I, González D, de Miguel MJ, Marín CM, Barberán M, Letesson JJ, Gorvel JP, Moriyón I, Blasco JM, Zygmunt MS (2009) Rough mutants defective in core and O-polysaccharide synthesis and export induce antibodies reacting in an indirect ELISA with smooth lipopolysaccharide and are less effective than Rev 1 vaccine against Brucella melitensis infection of sheep. Vaccine 27:1741-1749. https://doi.org/10.1016/j.vaccine.2009.01.025

34. OIE (2018) Brucellosis (Brucella abortus, B. melitensis and B. suis) (infection with B. abortus, B. melitensis and B. suis). NB: Version adopted in May 2016. In: Manual of Diagnostic Tests and Vaccines for Terrestrial Animals 2018 Off Int Epizoot, París, pp 1-44. https://www.oie.int/fileadmin/Home/fr/ Health_standards/tahm/3.01.04_BRUCELLOSIS.pdf

35. Muñoz PM, Estevan M, Marín CM, De Miguel MJ, Grilló MJ, Barberan M, Irache JM, Blasco JM, Gamazo C (2006) Brucella outer membrane complex-loaded microparticles as a vaccine against Brucella ovis in rams. Vaccine 24:1897-1905. https://doi.org/10.1016/j.vaccine.2005.10.042

36. Gil-Ramírez Y, Conde-Álvarez R, Palacios-Chaves L, Zúñiga-Ripa A, Grilló MJ, Arce-Gorvel V, Hanniffy S, Moriyón I, Iriarte M (2014) The identification of wadB, a new glycosyltransferase gene, confirms the branched structure and the role in virulence of the lipopolysaccharide core of Brucella abortus. Microb Pathog 73:53-59. https://doi.org/10.1016/j.micpath.2014. 06.002

37. Simon R, Priefer U, Pühler A (1983) A broad host range mobilization system for in vivo genetic engineering: transposon mutagenesis in Gram negative bacteria. Nat Biotechnol 1:784-791. https://doi.org/10.1038/ nbt1183-784

38. Aragón-Aranda B, de Miguel MJ, Lázaro-Antón L, Salvador-Bescós M, Zúñiga-Ripa A, Moriyón I, Iriarte M, Muñoz PM, Conde-Álvarez R (2020)
Development of attenuated live vaccine candidates against swine brucellosis in a non-zoonotic B. suis biovar 2 background. Vet Res 51:92, https://doi.org/10.1186/s13567-020-00815-8

39. Martínez-Gómez E, Stahle J, Gil-Ramírez Y, Zúñiga-Ripa A, Zaccheus M, Moriyón I, Iriarte M, Widmalm G, Conde-Álvarez R (2018) Genomic insertion of a heterologous acetyltransferase generates a new lipopolysaccharide antigenic structure in Brucella abortus and Brucella melitensis. Front Microbiol 9:1092. https://doi.org/10.3389/fmicb.2018.01092

40. Alton GG, Jones LM, Angus RD, Verger JM (1988) Techniques for the brucellosis laboratory. Institut National de la Reserche Agronomique, Paris, France. ISBN 2738000428

41. Grilló MJ, Manterola L, de Miguel MJ, Muñoz PM, Blasco JM, Moriyón I, López-Goñi I (2006) Increases of efficacy as vaccine against Brucella abortus infection in mice by simultaneous inoculation with avirulent smooth bvrS/bvrR and rough wbkA mutants. Vaccine 24:2910-2916. https://doi. org/10.1016/j.vaccine.2005.12.038

42. De Miguel MJ, Marín CM, Muñoz PM, Dieste L, Grilló MJ, Blasco JM (2011) Development of a selective culture medium for primary isolation of the main Brucella Species. J Clin Microbiol 49:1458-1463. https://doi.org/10. $1128 / \mathrm{jcm} .02301-10$

43. Lopez-Goñi I, García-Yoldi D, Marín CM, de Miguel MJ, Muñoz PM, Blasco JM, Jacques I, Grayon M, Cloeckaert A, Ferreira AC, Cardoso R, de Sa MIC, Walravens K, Albert D, Garin-Bastuji B (2008) Evaluation of a multiplex PCR assay (Bruce-ladder) for molecular typing of all Brucella species, including the vaccine strains. J Clin Microbiol 46:3484-3487. https://doi.org/10. 1128/jcm.00837-08

44. Muñoz PM, Boadella M, Arnal M, de Miguel MJ, Revilla M, Martínez D, Vicente J, Acevedo P, Oleaga A, Ruiz-Fons F, Marín CM, Prieto JM, de la Fuente J, Barral M, Barberán M, de Luco DF, Blasco JM, Gortazar C (2010) Spatial distribution and risk factors of Brucellosis in Iberian wild ungulates. BMC Infect Dis 10:46. https://doi.org/10.1186/1471-2334-10-46

45. OIE (2018) Ovine epidydimitis (Brucella ovis). Chapter 3.7.7. In: Manual of Diagnostic Tests and Vaccines for Terrestrial Animals (Version adopted by the world assembly of OIE delegates in May 2018). Paris, France. https:// www.oie.int/fileadmin/Home/fr/Health_standards/tahm/3.07.07_OVINE_ EPID.pdf

46. Riezu-Boj Jl, Moriyón I, Blasco JM, Gamazo C, Díaz R (1990) Antibody response to Brucella ovis outer membrane proteins in ovine brucellosis. Infect Immun 58:489-494. https://doi.org/10.1128/iai.58.2.489-494.1990

47. Pandey A, Cabello A, Akoolo L, Rice-Ficht A, Arenas-Gamboa A, McMurray D, Ficht TA, de Figueiredo P (2016) The case for live attenuated vaccines against the neglected zoonotic diseases Brucellosis and Bovine Tuberculosis. PLoS Negl Trop Dis 10:e0004572. https://doi.org/10.1371/journal. pntd.0004572

48. Barquero-Calvo E, Chaves-Olarte E, Weiss DS, Guzmán-Verri C, ChacónDíaz C, Rucavado A, Moriyón I, Moreno E (2007) Brucella abortus uses a stealthy strategy to avoid activation of the innate immune system during the onset of infection. PLoS One 2:e631. https://doi.org/10.1371/journal. pone.0000631

49. Conde-Alvarez R, Arce-Gorvel V, Iriarte M, Mancek-Keber M, BarqueroCalvo E, Palacios-Chaves L, Chacon-Diaz C, Chaves-Olarte E, Martirosyan A, von Bargen K, Grillo MJ, Jerala R, Brandenburg K, Llobet E, Bengoechea JA, Moreno E, Moriyon I, Gorvel JP (2012) The lipopolysaccharide core of Brucella abortus acts as a shield against innate immunity recognition. PLoS pathog 8:e1002675. https://doi.org/10.1371/journal.ppat.1002675

50. Fontana C, Conde-Álvarez R, Stahle J, Holst O, Iriarte M, Zhao Y, Arce-Gorvel V, Hanniffy S, Gorvel JP, Moriyón I, Widmalm G (2016) Structural studies of lipopolysaccharide defective mutants from Brucella melitensis identify a core oligosaccharide critical in virulence. J Biol Chem 291:7727-7741. https://doi.org/10.1074/jbc.M115.701540

51. Conde-Álvarez R, Arce-Gorvel V, Gil-Ramírez Y, Iriarte M, Grilló MJ, Gorvel JP, Moriyón I (2013) Lipopolysaccharide as a target for brucellosis vaccine design. Microb Pathog 58:29-34. https://doi.org/10.1016/j.micpath.2012. 11.011

52. Moriyón I, Grilló MJ, Monreal D, González D, Marín C, López-Goñi I, Mainar-Jaime RC, Moreno E, Blasco JM (2004) Rough vaccines in animal brucellosis: structural and genetic basis and present status. Vet Res 35:1-38. https://doi.org/10.1051/vetres:2003037

53. Grilló MJ, Blasco JM, Gorvel JP, Moriyón I, Moreno E (2012) What have we learned from brucellosis in the mouse model? Vet Res 43:29. https://doi. org/10.1186/1297-9716-43-29 
54. Martirosyan A, Moreno E, Gorvel JP (2011) An evolutionary strategy for a stealthy intracellular Brucella pathogen. Immunol Rev 240:211-234. https://doi.org/10.1111/j.1600-065X.2010.00982.x

55. Porte F, Naroeni A, Ouahrani-Bettache S, Liautard JP (2003) Role of the Brucella suis lipopolysaccharide $\mathrm{O}$ antigen in phagosomal genesis and in inhibition of phagosome-lysosome fusion in murine macrophages. Infect Immun 71:1481-1490. https://doi.org/10.1128/IAl.71.3.1481-1490.2003

56. Muñoz PM, Marín CM, Monreal D, Gonzalez D, Garin-Bastuji B, Diaz R, Mainar-Jaime RC, Moriyon I, Blasco JM (2005) Efficacy of several serological tests and antigens for diagnosis of bovine brucellosis in the presence of false-positive serological results due to Yersinia enterocolitica O:9. Clin Diagn Lab Immunol 12:141-151. https://doi.org/10.1128/CDLI.12.1.141151.2005

57. Brinley Morgan WJ, Littlejohn Al, MacKinnon DJ, Lawson JR (1966) The degree of protection given by living vaccines against experimental infection with Brucella melitensis in goats. Bull World Health Org 34:33-40

58. Pérez-Sancho M, Adone R, García-Seco T, Tarantino M, Diez-Guerrier A, Drumo R, Francia M, Domínguez L, Pasquali P, Álvarez J (2014) Evaluation of the immunogenicity and safety of Brucella melitensis B115 vaccination in pregnant sheep. Vaccine 32:1877-1881. https://doi.org/10.1016/j.vacci ne.2014.01.070

\section{Publisher's Note}

Springer Nature remains neutral with regard to jurisdictional claims in published maps and institutional affiliations.

- fast, convenient online submission

- thorough peer review by experienced researchers in your field

- rapid publication on acceptance

- support for research data, including large and complex data types

- gold Open Access which fosters wider collaboration and increased citations

- maximum visibility for your research: over $100 \mathrm{M}$ website views per year

At BMC, research is always in progress.

Learn more biomedcentral.com/submissions 